\title{
Aportes conceituais de referência ao planejamento metropolitano no Brasil contemporâneo
}

\section{Conceptual contributions reference to the Metropolitan planning in contemporary Brazil}

Ghissia Hauser-Doutora em Educação e Ciências da UFRGS. Mestre em Desenvolvimento Econômico e Social pela Université Paris 1, França. Arquiteta pela UFRGS. E-mail: ghissia@hotmail.com

Heleniza Campos - Doutorado em Geografia pela UFRJ. Mestre em Desenvolvimento Urbano pela UFPE. Arquiteta pela UFPE. Email: heleniza.campos@gmail.com

Diogo Onofre de Souza - Pós-Doutorado pela University of London, Inglaterra. Doutor em Bioquímica pela UFRJ. Mestre em Bioquímica pela UFRGS. Email: diogo.bioq@gmail. com

\section{Resumo}

A reestruturação das cidades do final do século XX é marcada por determinantes interurbanos e intraurbanos. A dinâmica das redes técnicas tende a substituir a estática dos lugares construídos, condicionando mentalidades e comportamentos urbanos; a interação dos indivíduos passa a ser reduzida e deslocalizada; o pertencimento a comunidades de interesses diversos não se funda mais nem sobre a proximidade nem sobre a densidade demográfica local. Nesse cenário, ocorre a aprovação do Estatuto da Metrópole, em janeiro de 2015, colocando as Regiões Metropolitanas (RMs) e Aglomerações Urbanas (AUs) brasileiras em lugar de destaque na agenda das ações sobre o urbano, exigindo uma maior compreensão sobre as novas lógicas de ocupação do território e suas relações com as atividades econômicas e sociais marcadas por redes e fluxos de alcances variados. A realidade metropolitana contemporânea nos conduz à necessidade de rever o conceito de região, bem como de pensar as novas centralidades urbanas.

\section{Palavras-chave}

Estatuto da Metrópole. Planejamento urbano. Planejamento metropolitano. Reestruturação urbana. Centralidade urbana.

\begin{abstract}
The urban restructuring in the late twentieth century is marked by intercity and intraurban determinatives. The dynamics of technical networks tends to replace the static places conditioning mentalities and urban behavior. The interaction between people becomes reduced and delocalized. Belonging to communities of diverse interests is no more based on proximity or even on the local demographic density. In that time is the approval of the metropolitain statute, in January 2015, that puts the Brazilian Metropolitan Regions (RMs) and Urban Agglomerations (AUs) in a prominent place on the urban agenda requiring a greater understanding of the new logic of occupation of the territory and its relations with the economic and social activities marked by networks and varied ranges of flows. The contemporary metropolitan reality leads us to review the concept of the region as well as centrality questions are placed.
\end{abstract}

\section{Keywords}

Metropolitain statute. Urban planning. Metropolitain planning. Urban restructuring. Urban centrality. 


\section{INTRODUÇÃO}

A história recente das regiões metropolitanas brasileiras está marcada pela pouca valorização das ações de planejamento metropolitano e pelo enfraquecimento e sucateamento das estruturas institucionais que trabalhavam com esse fim. A criação do Estatuto da Metrópole, por meio da Lei Federal $n^{\circ} 13.089$, de 12/01/2015, evidencia uma série de dificuldades para retomar o tema e as práticas de planejamento urbano e metropolitano, sobretudo em decorrência das transformações das metrópoles brasileiras que demandam novos instrumentos de planejamento urbano e metropolitano. Com isso, cria-se espaço para um importante debate sobre o planejamento e a gestão das metrópoles brasileiras.

Tratar esses temas como as bases conceituais para a escala regional; a relação entre planejamento metropolitano e a governança interfederativa; a articulação dos planos setoriais; o rebatimento territorial de diferentes políticas públicas, entre outros, não é tarefa trivial. Por essa razão, o debate sobre o Estatuto da Metrópole vem colocando vários temas em evidência, entre estes, ainda que pouco explorado na literatura, Klink (2012) destaca o processo de reestruturação produtiva na economia mundial e suas imbricações entre a emergência das metrópoles como motor da inovação e as relações entre metrópole, reestruturação produtiva e sustentabilidade.

Este artigo visa apresentar algumas reflexões teóricas que auxiliem na compreensão das lógicas de ocupação de um território metropolitano, profundamente relacionadas com as atividades econômicas e sociais e marcadas por redes e fluxos de alcances variados. A realidade metropolitana contemporânea nos conduz à necessidade de rever o conceito de região, bem como de pensar as novas centralidades urbanas na sociedade do conhecimento e da informação.

Nesta perspectiva, torna-se relevante revisar alguns aspectos da relação entre cultura técnica e forma urbana, bem como de alguns modelos de intervenção urbana ao longo do século XX, visando buscar elementos que contribuam para o enfrentamento da questão metropolitana no Brasil neste início do século XXI.

$\mathrm{O}$ artigo estrutura-se em quatro partes: a primeira discute o conceito de território no atual modelo de produção capitalista, tendo como referência o meio técnico-científico-informacional que caracteriza a sociedade contemporânea. A segunda parte aborda as transformações urbanas do território e como se estruturam as novas centralidades urbanas. A terceira parte discorre sobre o recém-aprovado Estatuto da Metrópole, quanto ao seu alcance e limitações e, por fim, a quarta parte apresenta as considerações finais. 


\section{O CONCEITO DE TERRITÓRIO DO FINAL DO SÉCULO XX E SUAS RELAÇÕES COM O MODELO DE PRODUÇÃO PÓS- FORDISTA}

No final do século XX, percebe-se que a dinâmica das redes técnicas tende a substituir a estática dos lugares construídos, condicionando mentalidades e comportamentos urbanos. A interação dos indivíduos passa a ser reduzida e deslocalizada. O pertencimento a comunidades de interesses diversos não se funda mais na proximidade, tampouco na densidade demográfica local. Trata-se da sociedade global, no seio da qual as noções de enraizamento e pertencimento local perderam a sua pertinência e devem ser repensadas em função de novos parâmetros, e segundo uma relação inédita com a temporalidade (CHOAY, 1999).

Os novos produtos, a aceleração da inovação tecnológica e a substituição da força de trabalho por máquinas possibilitaram a ampliação da capacidade produtiva das empresas. A incorporação de componentes tecnológicos que estimulou a produção de novas mercadorias gerou também a separação territorial entre as atividades de produção e as atividades de gestão. Novas necessidades foram criadas, o ciclo de vida dos produtos teve que ser diminuído e o financiamento para o consumo tornou-se pouco a pouco uma constante na vida dos consumidores. Com isso, surgem novas configurações nas empresas e nas cidades, o que demanda a análise das relações entre elas (SPOSITO, 2007).

Sposito (2007) enfatiza a importância de avaliar as repercussões do processo de globalização sobre o conjunto dos sistemas urbanos, considerando três aspectos extremamente relevantes: a associação entre mudanças na economia e mudanças no espaço; a articulação entre processos e formas; a necessidade de ampliar as escalas de análise.

Outra questão importante nesse debate são as transformações significativas da ideia de região. Há autores que falam na morte da região, tamanha a dificuldade de compreender os novos nexos regionais. Segundo Santos (1999), o conceito de região, configurado a partir das características relacionadas à identidade, cuja relação de solidariedade ocorre quase que exclusivamente em função dos arranjos locais, vem sendo considerado obsoleto. Para o autor, as novas definições de região têm por base os arranjos organizacionais sobre elas impostos, baseados em racionalidades de origens distantes, ou seja, as regiões tornaram-se lugares funcionais de um todo, como espaços de conveniência, que se distinguem umas das outras pela sua coerência funcional. A região continua existindo, mas o seu nível de complexidade ampliou-se significativamente, visto que nenhum subespaço do planeta pode escapar ao processo conjunto de globalização, fragmentação/ 
individualização e regionalização. Isso permite afirmar que a interdependência universal dos lugares é a nova realidade do território (SANTOS, 1999).

Diante disso, Santos (1999) afirma que os arranjos espaciais não são mais apenas espaços contínuos e contíguos como nas regiões do passado. Ao lado dessas manchas - ou acima delas - há constelações de pontos descontínuos que estão interligados, definindo um espaço de fluxos reguladores e que, segundo o autor, abrem espaço para novas categorias analíticas, tais como as horizontalidades e as verticalidades. As horizontalidades correspondendo à definição tradicional de região com extensões contínuas, em que a solidariedade entre os elementos formadores deve-se, sobretudo, ao processo direto de produção; e as verticalidades correspondendo a pontos no espaço que, separados uns dos outros, asseguram o funcionamento global da sociedade e da economia, em que a solidariedade ocorre através da circulação, do intercâmbio, de suas regulações e das redes.

Segundo Santos (1999), a ciência, a tecnologia e a informação encontramse na base da produção, da utilização e do funcionamento do espaço, podendose afirmar que a informação é o principal vetor do processo social e que, consequentemente, os territórios são equipados para facilitar a sua circulação. $O$ espaço reservado ao processo direto da produção vem se restringindo, enquanto se amplia o espaço das outras instâncias da produção: circulação, distribuição e consumo. Além disso, há um processo de especialização, com áreas onde a produção de certos itens é mais vantajosa, aumentando a necessidade de intercâmbio. Dessa forma, ampliam-se as possibilidades técnicas e organizacionais para a transferência de produtos e de gestão à distância, fazendo com que essas especializações produtivas sejam mundialmente solidárias. Alguns lugares tendem a tornar-se especializados; e isso se deve mais às condições técnicas e sociais do que aos recursos naturais. Com isso, surge a noção de produtividade espacial ou produtividade geográfica relacionada a uma atividade ou a um conjunto de atividades (SANTOS, 1999).

Klink (2012) problematiza esse debate ao mencionar que as dimensões territoriais do processo de inovação deslocaram-se para fora do objeto da empresa e da unidade produtiva, assumindo uma abordagem epistemológica na qual a metrópole e os seus múltiplos agentes e interesses desempenham um papel privilegiado como lócus de inovação. O autor também agrega contribuições de autores associados à literatura sobre clusters, como Porter (1986), e sobre arranjos produtivos locais, sistemas produtivos e inovativos locais, como Lastres e Cassiolato (2003), que ressaltaram, da mesma forma, os entrelaçamentos da dinâmica setorial (concentração de atividades econômicas em setores correlatos) e territorial (o ambiente produtivo propício à inovação da metrópole). Segundo 
Klink (2012), abre-se assim a perspectiva de um campo de reflexão relativamente novo, que tangencia diversas áreas do conhecimento, como planejamento urbano, ciência, tecnologia e sociedade, ciência política e sociologia, entre outros aspectos, cujos contornos ainda estão muito pouco explorados.

O deslocamento do debate citado por Klink (2012), sobre as dimensões territoriais do processo de inovação para fora da empresa e da unidade produtiva, evidencia-se em Lundvall (2007), que enfatiza a importância de uma abordagem nacional para a questão da inovação e a relevância dos sistemas regionais e setoriais de inovação, dos arranjos produtivos locais / clusters industriais e da Triple Helix. Este último conceito, definido por Etzkowitz \& Leydesdorff (2000), trata das relações universidade/empresa/governo no sistema local de inovação e da importância das universidades na produção de conhecimentos associados à resolução de problemas do setor empresarial, bem como na comercialização dos resultados dessa produção (SALERNO, 2012). A literatura que trata do fenômeno de interação e cooperação nas aglomerações produtivas criou uma diversidade de nomenclaturas para designar essas aglomerações, dentre as quais se destacam os clusters, arranjos produtivos locais, distritos industriais, polos e parques tecnológicos, milieu inovador e outras variações (LASTRES; CASSIOLATTTO, 2003).

\section{TRANSFORMAÇÕES DOS TERRITÓRIOS URBANOS E NOVAS CENTRALIDADES}

Região urbana, comunidade urbana, distrito urbano, são novas entidades que, segundo Choay (1999), fazem pensar no desaparecimento da noção de cidade, da forma como foi entendida e conceituada, sobretudo na fase industrial do capitalismo. O anacronismo de "comuna", "aldeia", "cité" - são termos que, em breve, remeterão apenas à história ou a nostalgias carregadas de sentido (CHOAY, 1999).

Whitaker (2007) destaca que os fluxos (de mercadorias, pessoas e capitais) promovidos pelo atual estágio do capitalismo influenciam fortemente a organização dos espaços intra e interurbanos. E isso implica em mudanças no padrão produtivo, que estão associadas às novas territorialidades na estrutura das cidades e das redes urbanas. Nesse sentido, o autor destaca que a nova relação centro-periferia seria caracterizada por três dinâmicas principais: a primeira seria a dinâmica imposta pelas novas lógicas de comportamento espacial das empresas industriais, redefinindo não apenas o tecido interno das aglomerações urbanas, mas também a rede de fluxos entre aglomerações de diferentes portes (SPOSITO, 1999); a segunda diz respeito aos fluxos entre diferentes unidades da 
mesma empresa e entre empresas controladas sob o mesmo capital, que geram o interesse na maior articulação entre as unidades de gestão de uma empresa ou grupo e outras empresas e/ou instituições de diversos portes, para a compra de produtos e serviços de diferentes naturezas (SPOSITO, 1999), gerando estratégias de localização que se dão, primordialmente, pela incorporação de novas áreas ao tecido urbano ou pela localização nas franjas e periferias, notadamente em nós de circulação e, muitas vezes, atendendo a vários municípios; a terceira refere-se à ocupação de áreas degradadas de grandes cidades, outrora destinadas a outros usos (equipamentos industriais, portos, etc.), que geralmente são colocadas à disposição a custos relativamente baixos e que, não raro, exigem pesados investimentos públicos para a sua revitalização ou readequação (WHITAKER, 2007).

Essas três dinâmicas operam, a nosso ver, em várias escalas diferentes e, muitas vezes, só por meio da articulação entre escalas se tornam identificáveis ou desmistificáveis, o que revela a importância da compreensão dessas duas realidades para se compreender a estruturação interna das cidades. Complementarmente, devemos compreender que a relação em dimensões e níveis diferentes - na constituição da rede de cidades e entre redes, as formas de circulação materiais e os meios de transporte são complementados pelas circulações imateriais. O que implica em se compreender que ao conjunto de usos se sobreponha e se contraponha, por vezes, a dinâmica dos fluxos (WHITAKER, 2007, p. 8).

Nesta perspectiva, é possível estabelecer associações diretas entre técnicas, tecnologias e a constituição de novas centralidades urbanas. Para o autor, a compreensão de como se dá a organização das empresas, a complexidade de seus sistemas de informação e sua inserção na estrutura da cidade pode auxiliar na identificação de novos elementos definidores da centralidade e da reestruturação urbanas. Para a análise da reestruturação urbana, o autor considera a necessidade de privilegiar a dimensão econômica e, nesse sentido, a dinâmica de localização e as relações econômicas estabelecidas entre e pelas diferentes empresas constitui importante indicador (WHITAKER, 2007).

Para se compreender a constituição da centralidade, mais do que a localização, o autor considera que os elementos determinantes são os fluxos, pois esses, incrementados pelas comunicações e telecomunicações, geram decisões, trocas, gestão, controle e irradiação de valores. Dessa forma, a centralidade é a expressão da dinâmica de definição/redefinição das áreas centrais e dos fluxos no interior da cidade, das escalas da aglomeração e da rede urbana. (WHITAKER, 2007).

Sua concepção, assim, não é una e abarca várias escalas e, sobretudo, a articulação destas através de duas argumentações básicas: a cidade se organiza articulada em redes de produção e numa relação e articulação 
intra-urbana e interurbana; a cidade possui estruturas morfológicas e sociológicas e, nesse sentido, a centralidade também diz respeito a um lugar com conteúdo social, carregado de símbolos e representações. A centralidade é esse processo duplo que se expressa também pela organização de vazios, de concentração e dispersão, como aponta Lefebvre (1983, p. 46) (WHITAKER, 2007, p. 3).

Whitaker (2007) ressalta que a morfologia da cidade tem correlação com o desenho da rede urbana, e que essa característica não é exclusiva do momento atual da urbanização. A cidade mononuclear estava atrelada à hierarquia urbana clássica, dos centros principais e centros secundários, onde havia a estrutura necessária para organizar a produção e o consumo. Segundo o autor, "atualmente, lança-se mão da tecnologia e dela se serve e a ela induz o sistema hegemônico mundial. Isso implica em mudanças no padrão de produção, associadas às novas territorialidades" (WHITAKER, 2007).

\section{PLANOS METROPOLITANOS, O ESTATUTO DA METRÓPOLE E A DIMENSÃO TERRITORIAL E REGIONAL NA CONTEMPORANEIDADE}

A Lei $n^{\circ}$ 13.089, de 12 de janeiro de 2015 instituiu o Estatuto da Metrópole, estabelecendo diretrizes gerais para: (i) o planejamento, a gestão e a execução das Funções Públicas de Interesse Comum (FPIC) em Regiões Metropolitanas (RMs) e Aglomerações Urbanas (AUs) instituídas pelos Estados; (ii) normas gerais sobre o Plano de Desenvolvimento Urbano Integrado e outros instrumentos de governança interfederativa; (iii) critérios para o apoio da União a ações que envolvam governança interfederativa no campo do desenvolvimento urbano, abrindo espaço para um importante debate nacional sobre alcances e limitações dessa lei, bem como sobre perspectivas para o planejamento e a gestão das metrópoles brasileiras.

A nova lei apresenta dez novos Instrumentos de Desenvolvimento Urbano Integrado, adicionais aos apresentados pelo Estatuto da Cidade, sendo que o primeiro, e um dos mais desafiadores é o Plano de Desenvolvimento Urbano Integrado (PDUI), cujo prazo para execução é de três anos. Os novos planos metropolitanos deverão conter o seguinte conteúdo mínimo:

I - as diretrizes para as Funções Públicas de Interesse Comum (FPIC), incluindo projetos estratégicos e ações prioritárias para investimentos;

II - o macrozoneamento da unidade territorial urbana;

III - as diretrizes quanto à articulação dos Municípios no parcelamento, uso e ocupação no solo urbano; 
IV - as diretrizes quanto à articulação intersetorial das políticas públicas afetas à unidade territorial urbana;

$\mathrm{V}$ - a delimitação das áreas com restrições à urbanização visando à proteção do patrimônio ambiental ou cultural, bem como das áreas sujeitas ao controle especial pelo risco de desastres naturais, se existirem;

VI - o sistema de acompanhamento e controle de suas disposições.

O estabelecimento de um prazo para que as regiões metropolitanas elaborem seus PDUIs lembra o recente processo ocorrido com a promulgação do Estatuto da Cidade (Lei no 10.257/2001). Esse último exigia a realização de um Plano de Desenvolvimento Urbano Municipal (PDUM) em todos os municípios com mais de vinte mil habitantes ou aqueles que apresentassem algumas especificidades, tais como as cidades com potencial turístico. O principal objetivo do PDUM é estabelecer uma estratégia para a intervenção imediata, com base em alguns princípios claros de ação para o conjunto de agentes envolvidos na construção da cidade, servindo também como elemento para a gestão pactuada da cidade (ESTATUTO DA CIDADE, 2001). Durante o processo de elaboração dos PDUMs muitos municípios vivenciaram uma série de dificuldades, tanto para definir suas estratégias de desenvolvimento urbano quanto para adequar o rebatimento territorial de suas diretrizes e instrumentos.

Santos Jr. e Montandon (2011) analisaram um conjunto de PDUMs e concluíram que, apesar dos avanços ocorridos na definição de instrumentos normativos, fiscais e de gestão, os municípios tiveram dificuldades para construir o diálogo com a cidade real, com os problemas urbanos e com a efetiva capacidade de gestão do município. Esse processo revelou inúmeras limitações, tais como: (i) precariedade no rebatimento territorial das diretrizes e instrumentos estabelecidos nos Planos Diretores e o descolamento dos propósitos do plano com o território municipal; (ii) dificuldade para a implementação dos instrumentos voltados à promoção do direito à cidade e para a sua gestão democrática; (iii) pouca ou nenhuma inovação na relação das estratégias de ordenamento territorial e sustentabilidade ambiental; (iv) dificuldade para o enfrentamento dos conflitos vinculados à dinâmica de operacionalização das unidades de conservação integral e de outras categorias de áreas de interesse ambiental urbanas e rurais; (v) dificuldade para instituir mecanismos e instrumentos de democratização do orçamento municipal. Além disso, a maioria dos planos diretores foi realizada unicamente por técnicos e por determinados grupos da sociedade, não sendo eficaz para o enfrentamento dos problemas urbanos. Ou seja, além da 
baixa legitimidade, a maior parte dos planos não expressava um pacto para o desenvolvimento urbano do município (SANTOS Jr.; MONTANDON, 2011).

Quanto aos municípios situados em regiões metropolitanas, os Planos Diretores fizeram referência à questão metropolitana em uma diversidade de temas, tais como: (i) Política Ambiental, ao tratar da gestão de bacias hidrográficas, de Unidades de Conservação e, particularmente, das Áreas de Preservação Permanente (APPs); (ii) transportes, em questões relativas ao traçado e à hierarquia dos sistemas viários; e (iii) uso e ocupação do solo, nas definições relativas aos limites e interseções de zonas urbanas e não urbanas, polaridades, multipolaridades e especializações de funções urbanas envolvendo mais de um município. No entanto, esses temas foram tratados de forma superficial e, apesar do reconhecimento da necessidade de articulação federativa, em geral, a tendência foi de privilegiar a articulação vertical com a União e com os Estados, em detrimento da articulação horizontal entre os municípios (SANTOS Jr.; MONTANDON, 2011).

Além disso, os municípios encontraram grandes dificuldades em avançar no sentido da construção e implementação de modelos de planejamento e gestão metropolitana que envolvessem arranjos institucionais de gestão e fundos. A fragilidade dos Planos Diretores, no que se refere à questão metropolitana, pode ser creditada à insuficiência das definições relativas ao papel dos governos estaduais na gestão metropolitana e na promoção de um planejamento municipal articulado à gestão metropolitana (SANTOS Jr.; MONTANDON, 2011).

Em virtude dessa experiência, avalia-se que a elaboração dos planos metropolitanos deverá evidenciar um novo conjunto de dificuldades decorrentes de: (i) trabalhar com a escala metropolitana; (ii) ausência de equipes e atividades de planejamento metropolitano na maioria das instituições brasileiras, após um longo período de pouca valorização dessa atividade no Brasil; (iii) necessidade de identificar formas de instituição das FPICs de maneira concertada, entre municípios que têm autonomia garantida; (iv) necessidade de articulação desse plano com os demais planos setoriais e com as políticas de desenvolvimento econômico, dentre outras.

A experiência dos Planos Diretores Municipais do Estatuto da Cidade, associada à ação de diversos atores, contribuiu para a aprovação da Lei n ${ }^{\circ} 13.089$, de 12 de janeiro de 2015, que instituiu o Estatuto da Metrópole. Essa medida vem colocando as Regiões Metropolitanas (RMs) e Aglomerações Urbanas (AUs) em lugar de destaque na agenda das ações sobre o urbano, estimulando o debate sobre as configurações mais complexas da metropolização brasileira. Outro tema que se coloca é a necessidade de diálogo com a Política Nacional 
de Desenvolvimento Regional, visto que muitas das RMs institucionalizadas decorrem de intenções que se lastreiam em estratégias de desenvolvimento regional (MOURA; HOSHINO, 2015).

Considerando que a maioria dos Planos de Desenvolvimento Urbano Municipal teve baixa legitimidade, não expressando um pacto para o desenvolvimento urbano dos municípios (SANTOS Jr.; MONTANDON, 2011), urge a ampliação do debate para a definição de diretrizes que orientem a elaboração dos planos metropolitanos. Nesse sentido, cabe elencar alguns aspectos relevantes no que se refere ao território e à região, que não foram tratados no Estatuto da Metrópole.

Com referência ao quadro metropolitano oficial, Ribeiro, Santos Júnior e Rodrigues (2015) questionam a sua legitimidade funcional, em decorrência da proliferação das RMs nos Estados. Há 78 regiões metropolitanas institucionalizadas no Brasil e a lei não exige que estas sejam redefinidas. Além disso, os autores salientam que:

[...] não houve a preocupação de constituir critérios para identificar o território funcional de cada metrópole, compreendido pelos municípios que efetivamente têm relações de interpendência no plano da produção, do mercado de trabalho e da vida coletiva (RIBEIRO; SANTOS JÚNIOR; RODRIGUES, 2015).

A experiência do Estatuto da Cidade mostrou que os Planos Diretores dos municípios situados em regiões metropolitanas demonstraram as dificuldades de tratar a questão regional, ao abordar, de forma superficial, temas como limites e interseções de zonas urbanas e não urbanas, polaridades, multipolaridades e especializações de funções urbanas envolvendo mais de um município (SANTOS Jr; MONTANDON, 2011). Para avançar nesses temas, a lei parece não levar em consideração as profundas mudanças na morfologia urbana, que, segundo Withaker (2007), denunciam um modelo de cidade que não é mais contíguo e concentrado e que, aparentemente, poderia levar a se pensar num processo de urbanização homogêneo.

Essa nova morfologia urbana reorganiza, de maneira aparentemente contraditória, a dispersão e a aglomeração, numa dinâmica que cria e recria centralidades num movimento que é poli(multi)cêntrico, como apontou Lefebvre (1962), à medida que se organiza não apenas com muitos centros, mas também com centros de conteúdos diferenciados. Portanto, para se compreender a realidade urbana, devem-se somar aos conceitos tradicionais, conceitos específicos, tais como o de rede (de intercâmbio, de comunicação). A definição do fenômeno 
urbano implica considerar também as justaposições e superposições de redes, o encontro e a reunião dessas redes - umas constituídas em função do território, outras em função da indústria e outras, finalmente, em função dos demais centros da malha urbana (LÉFÈBVRE, 1982, p. 127-128; WITHAKER, 2007, p.5).

Moura (2015) chama a atenção para outro tema não tratado na lei, ao se referir às novas categorias territoriais, como os grandes arranjos espaciais descontínuos, que reúnem conjuntos de aglomerações e centros e, por vezes, mais de uma metrópole. Esses arranjos assumem papéis de comando regional e até nacional na divisão social do trabalho, reunindo massas expressivas de população e a incidência concentrada do volume de demandas desatendidas. Ou seja, o nível de complexidade das regiões ampliou-se expressivamente e a interdependência universal dos lugares é a nova realidade do território (SANTOS, 1999). Além disso, Moura (2015) salienta que o Estatuto da Metrópole perdeu a chance de determinar outras exigências aos Estados, tais como: (i) a oficialização de RMs e AUs mediante consolidação comprovada; (ii) a estipulação de prazo para a organização do arranjo interfederativo e a implantação da gestão plena; (iii) a compatibilização dos demais planos setoriais ao Plano de Desenvolvimento Urbano Integrado.

Se por um lado o Estatuto da Metrópole coloca as Regiões Metropolitanas (RMs) e Aglomerações Urbanas (AUs) em lugar de destaque na agenda das ações sobre o urbano, ao estimular o debate sobre as configurações mais complexas da metropolização brasileira e o diálogo com a Política Nacional de Desenvolvimento Regional (MOURA; HOSHINO, 2015), por outro, as exigências do Estatuto da Metrópole impõem um prazo muito exíguo para a elaboração dos PDUIs. Tarefas como a análise da conjuntura metropolitana, a escolha da base conceitual, a discussão sobre o modelo de planejamento a ser adotado nas regiões metropolitanas brasileiras, entre outras ações, demandam importantes reflexões, bem como a recomposição de equipes de trabalho e, em alguns casos, de instituições responsáveis pelo planejamento metropolitano nos Estados.

\section{CONSIDERAÇÕES FINAIS}

As regiões metropolitanas brasileiras constituem territórios de complexidades muito distintas. Além disso, passam por um conjunto de transformações significativas devido ao impacto da reestruturação produtiva, com relocação de atividades produtivas, que geram fluxos materiais e imateriais e novas configurações socioespaciais. Neste contexto, o Estatuto da Metrópole 
(2015) estabelece alguns desafios relativos à reconfiguração de importantes conceitos e práticas, tais como o planejamento metropolitano.

O texto discute a necessária revisão de antigos conceitos como território, região e redes tecnológicas e informacionais, que devem ser observados à luz da reestruturação produtiva e de seus impactos em escala metropolitana, tais como o processo de reorganização de atividades estratégicas (principalmente industriais e serviços), alterações na estrutura do mercado de trabalho e as configurações socioespaciais que resultam dos fluxos de pessoas, mercadorias e informações.

A RM também enfrenta os problemas decorrentes do esgotamento do modelo anterior de gestão e planejamento, acompanhado da redução da capacidade decisória do organismo metropolitano. Se por um lado, ainda não foram resolvidos problemas antigos, a complexidade da situação atual acrescentou outros, cuja solução não é exclusivamente técnica. Em um contexto de forte tradição municipalista, desde o início dos anos 1990, multiplicaram-se no Estado as iniciativas no sentido de efetivar a participação da sociedade em diferentes níveis e formas, para a formulação, implementação e acompanhamento de políticas públicas, inclusive as que dizem respeito à gestão metropolitana.

Nos âmbito dos municípios e, mais recentemente, também dos Estados, têm surgido práticas inovadoras, das quais a mais conhecida e analisada é o Orçamento Participativo de Porto Alegre, vigente desde 1989, e hoje já adotado por vários municípios, principalmente da RMPA. No âmbito estadual, destaca-se a implantação dos Conselhos Regionais de Desenvolvimento (Coredes), seguidos da Consulta Popular, do Orçamento Participativo Estadual e do Fórum Democrático. Transcorrida mais de uma década do início desse processo, esse conjunto de experiências de gestão cooperativa, com seus diferentes instrumentos, constitui uma fonte de ensinamentos sobre como enfrentar os problemas e produzir soluções negociadas, capazes de garantir condições de governabilidade e governança.

Moura (2015) destaca que a nova lei não contempla a diversidade de configurações espaciais do processo de metropolização brasileiro, focando apenas nas RMs e AUs, incluindo as regiões de fronteira. Os grandes arranjos espaciais descontínuos, que abrangem conjuntos de aglomerações e centros urbanos, por vezes mais de uma metrópole, ainda estão por ser analisados. De qualquer forma, a nova lei disciplina a institucionalização e a governança dessas unidades territoriais urbanas nos estados, penalizando autoridades pelo descumprimento de seus dispositivos, o que traz um importante avanço com relação ao estatuto existente (MOURA; HOSHINO, 2015). 
O momento atual de reestruturação produtiva da economia mundial e de aceleração das dinâmicas de informação, comunicação e inovação abrem, ao mesmo tempo, limites e potencialidades para as metrópoles (KLINK, 2012). Neste contexto, percebe-se que o Estatuto da Metrópole não trata de questões relativas às novas formas de uso e ocupação do território decorrentes do novo modelo de produção (trabalho em rede, trabalho em cooperação, APLs, parques tecnológicos, etc.).

A breve reflexão sobre planejamento metropolitano, relações entre territórios, modelos produtivos e inovações, com destaque para novos conceitos de região (SANTOS, 1999) e as transformações dos territórios e novas centralidades urbanas (WITHAKER, 2007) e, mais recentemente, a discussão sobre as imbricações entre o processo de reestruturação produtiva na economia mundial e a emergência das metrópoles como motor da inovação em Klink (2012), reforçam a ideia de que para avançarmos nas reflexões sobre planejamento metropolitano é fundamental compreender os processos de reestruturação urbana que vem ocorrendo nas metrópoles brasileiras e, para tanto, buscar o entendimento das transformações territoriais decorrentes das atividades econômicas. Nesse sentido, Withaker (2007) destaca que a dinâmica de localização e as relações econômicas estabelecidas pelas e entre as diferentes firmas constitui um importante indicador para a compreensão do território.

Nesse ambiente institui-se o Estatuto da Metrópole, visando disciplinar a institucionalização e a governança de unidades territoriais urbanas nos Estados, bem como penalizar autoridades de diferentes escalões pelo descumprimento de seus dispositivos. A instituição da lei, por si, representa um avanço. No entanto, as ideias de região metropolitana e de plano metropolitano embutidas na lei abrem espaço para vários questionamentos.

A experiência do Estatuto da Cidade e a exigência de implantação do PDUM a partir do diálogo com a cidade real, com os problemas urbanos e com a efetiva capacidade de gestão do município, mostrou que a imposição dos planos diretores não é suficiente para um verdadeiro avanço das atividades de planejamento urbano municipal. Seus resultados caracterizam-se pela baixa legitimidade e por não expressar um pacto para o desenvolvimento urbano do município (SANTOS Jr.; MONTANDON, 2011). 


\section{REFERÊNCIAS}

CHOAY, F. O reino do urbano e a morte da cidade. Projeto História, São Paulo, v. 18, p. 67-89, 1999. Disponível em: <file://C:/Users/ghissia-hauser/ Downloads/10977-26958-1-SM\%20(3).PDF>. Acesso em: 7 mar. 2016.

ESTATUTO DA CIDADE. Lei Federal no 10.257, de 10 de julho de 2001. Disponível em: <http://www.planalto.gov.br/ccivil_03/leis/LEIS_2001/

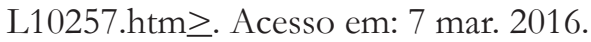

ESTATUTO DA METROPOLE. Lei Federal $\mathbf{n}^{\mathbf{0}} \mathbf{1 3 . 0 8 9}$, de 12 de janeiro de 2015. Disponível em: < http://www.planalto.gov.br/ccivil_03/_Ato2015-

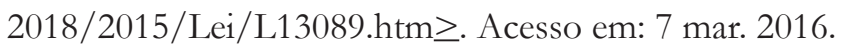

ETZKOWITZ, H.; LEYDESDORFF, L. The dynamics of innovation: from National Systems and "Mode 2" to a Triple Helix of university-industrygovernment relations. Research Policy, n. 29, 2000.

KLINK, J. Os territórios da inovação. Retomando o debate (normativo) sobre a experiência do $\mathrm{ABC}$ paulista, Revista Contemporâneo, São Paulo, n. 9, 2012. Disponível em: < http://www.revistacontemporaneos.com.br/n9/dossie/ territorios-inovacao.pdf $\geq$. Acesso em: 10 abr. 2016.

LASTRES, H. M. M.; CASSIOLATO, J. E. Glossário de arranjos e sistemas produtivos e inovativos locais. Rio de Janeiro: UFRJ, 2003.

LUNDVALL, B. Postscript: innovation system research: where it came from and where it might go. Aalborg: [s.n.], 2007.

MOURA, R.; HOSHINO, T.A.P. Estatuto da Metrópole: enfim, Aprovado! Mas o que oferece à metropolização brasileira? In: Observatório das Metrópoles. Brasília: INCT/CNPq, 2015.

PORTER, M. E. Estratégia competitiva: técnicas para análise de indústrias e da concorrência. 17. ed. Rio de Janeiro: Campus, 1986.

RIBEIRO, L. C. Q.; SANTOS Jr. O. A.; RODRIGUES, J. M. Estatuto da Metrópole: o que esperar? Avanços, limites e desafios In: Observatório das Metrópoles. Brasília: INCT/CNPq, 2015.

SALERNO, M. S. Inovação tecnológica e trajetória recente da política industrial. Revista USP, São Paulo, n. 93, p. 45-58, mar.-maio, 2012. 
SANTOS JR., O. A.; MONTANDON, D. T. (Org.). Os planos diretores municipais pós-estatuto da cidade: balanço crítico e perspectivas. Rio de Janeiro: Letra Capital; Observatório das Cidades: IPPUR/UFRJ, 2011.

SANTOS, M. Modo de Produção técnico-científico e diferenciação espacial. Revista Território, Rio de Janeiro, n. 6, 1999.

SPOSITO, M. E. B. A urbanização da sociedade: reflexões para um debate sobre as novas formas espaciais. In: DAMIANI, A. L.; CARLOS, A. F. A.; SEABRA, O. C. L. O espaço no fim do século: a nova raridade. São Paulo: Contexto, 1999.

Cidades médias: reestruturação da cidade e reestruturação urbana. In: SPOSITO, M. E. B. (Org.). Cidades médias: espaços em transição. São Paulo: Expressão Popular, 2007.

WHITACKER, A. M. Inovações Tecnológicas, Mudanças nos Padrões Locacionais e na Configuração da Centralidade em Cidades Médias. Revista Electrónica de Geografía y Ciencias Sociales, Barcelona, n. 245, 2007. 
